Reply

Dear SirS

Dr Medley's point seems very reasonable. Dr Hotopf is right to point out that offensive comments appear not only in case-notes, but in scientific papers, a matter beyond the scope of our study, but which responsible editors should probably take more seriously. Although we did not ask medical patients to rate labels such as "a diabetic", we suspect that Dr Hotopf may be right in thinking that they too might find these offensive.

Drs Howard \& Lovestone seem to have misunderstood when they assert that "contrary to the conclusions of this study most psychiatrists do not write offensive comments in case-notes." What we concluded was that most of the psychiatric case-notes we examined contained offensive comments and not that most psychiatrists write offensive comments in case-notes. Although we did not attempt to find out how many offensive comments individual psychiatrists or physicians made, our impression was, not surprisingly, that some made considerably more than others and many none at all.

Howard \& Lovestone speak of the "silliness" of what the authors deemed to be offensive. The point is not so much whether comments which the authors rated as extremely offensive are "silly" or not, but that patients themselves rated the comments as extremely offensive. Howard \& Lovestone's secretary thought the comments merely "offensive": perhaps she is so used to typing rude comments (viz: "downright silliness") that she no longer raised an eyebrow.

Queen Mary's University Hospital

Roehampton Lane

London SWI5 SPN

Athanassios Douzenis

Gorden Hospital

Bloomburg Street

London SWIV $2 R H$

West Middlesex University Hospital

TIMOTHY HUGHES

Isleworth

Middlesex TW76AF

SHôn LeWis

Charing Cross and Westminster Medical School St Dunstan's Road

London W6 8RP

\section{Patient dispersal}

Dear Sirs

The recent survey by Benbow \& Jolley (Psychiatric Bulletin, 1992, 16, 533-535) and response by Murphy
\& McDonald (Psychiatric Bulletin, 1992, 16, 801802 ) suggest that, contrary to the usual course, Britain is following in American footsteps in development of what Ralph Footring (Psychiatric Bulletin, 1992, 16, 795-796) would have us call "patient dispersal."

As a result of the patient dispersal movement in the United States there was discharge of the mentally ill from state hospitals to nursing homes. The population of the former changed from $1,500,000$ to 500,000 and of the latter from 500,000 to $1,500,000$. A lot of studies were done (Birkett, 1991) and these mostly concluded that the mentally ill did badly in nursing homes. This led to the passage of a rider to the Omnibus Budget Reconciliation Act of 1987. The legislation, commonly called OBRA'87, was designed, according to its originator, Senator Waxman to "stop dumping the mentally ill into nursing homes". It also imposed onerous restrictions on the prescribing of psychotrophic drugs in nursing homes.

The terminology adopted by the South London Family Housing Association for their homes containing 12 seriously disabled people, with consultant input, is intriguing. The question must now arise of how many patients, and how much consultant input, a domus must have before it is called, if you will forgive the expression, an asylum.

2 Copeland Drive

D. Peter Birkett

Suffern

New York 10901, USA

Reference

BuRketr, D. P. (1991) Psychiatry in the Nursing Home. New York: Haworth Press.

\section{Response of management and patients to loss of unit}

DeAR Sirs

I was impressed with Alison Wood's perspective on her training placement as a senior registrar at an adolescent psychotherapy unit which was about to close (Psychiatric Bulletin, 1992, 16, 547-548). Much that she describes resonates with my own experience as the consultant in charge of a day therapeutic community. More than with adolescents, who at least can be seen politically as holding potential for the future, the kind of patients we treat on a long-term basis can be seen as a drain on dwindling resources; not much of an asset in the brave new world of the market economy in the NHS.

$\mathrm{My}$ anxieties on this topic were recently brought into focus by a serious fire in the lovely Victorian house where the unit was based. The response of 
many in management to our chaos and loss was less than impressive, regarding it as a serious nuisance in financial terms and haggling over which budget resources may be squeezed from. On the day after the fire, the patients had to be met outside the unit, the situation explained to them, and they were then escorted to the general psychiatric unit where we were allowed to borrow a room for a couple of days. On requesting tea and coffee for the patients, the charge nurse said "Is this authorised?; which budget is it from; you'll have to pay for this". Maybe we need to learn a lesson in humanity from our patients: I rang a number of out-patients to cancel their appointments and explain what had happened; typically the response was "How dreadful, thank goodness no one was hurt, is there anything that would help?"' I know which response I prefer.

Red House

Psychotherapy Services

c/o Prestwich Hospital

Manchester M25 $7 B L$

\section{Community care in England and Wales - an Eastern perspective}

DEAR SIRS

We have noted a marked contrast in the care of mentally ill and mentally handicapped people in India and the United Kingdom over the past 12 years. In India, a tiny minority of these patients have institutional care as most are looked after by their families in their own homes, usually in the setting of extended/joint families.

In the United Kingdom mental hospitals have cared for an otherwise difficult to care for group by the development of a subculture, a community in itself within the walls of the hospital where each ward could be compared to a large extended family house of an eastern society. If we visualise a traditional large hospital from this perspective, the transition from "hospital to community" becomes a misnomer. It is a mere change from one community setting to another, from a large extended family to a small nuclear family.

One may argue for and against the two types of family settings. One system may have greater independence, freedom of movement, less hierarchy and greater opportunity while the other has inbuilt social support harbouring interdependence. When it comes to caring for disabled persons, a nuclear family system will fail as it lacks cohesion and sharing of the task in hand. Such care can only be provided in a setting comparable to an eastern extended family.

In a society where the majority of people live in small nuclear family units, the existence of large hospitals seems a paradox. The two tier system then becomes unbearable to society at large.

The care of the people with learning disabilities in small ordinary houses has seemed acceptable to the non-disabled section of the population, the planners and the carers. It is debatable, in our view, whether it offers the best environment for care as perceived by those at the receiving end.

M. Agarwal

A. Kumar

Calderstones Hospital

Whalley

Blackburn BB6 9PE

\section{'Di Pietro syndrome': psychopathology, mass media, and the Italian bribes scandal}

DeAR Sirs

D. N. Protheroe (Psychiatric Bulletin, 1992, 16, 807) reported on a case where a mass media event such as the Wimbledon Tennis Championship was incorporated into a patient's psychopathology.

We would like to describe a similar case related to the mass media coverage of the Italian bribes scandal, the most ambitious political corruption clean-up ever, described by international newspapers since the beginning of 1992 (Phillips, 1992; Bannon, 1992). Antonio Di Pietro, the magistrate leading the investigation, discovered a wide network of illegal kickbacks and bribes on state-funded projects and nearly every day politicians and businessmen have been jailed and hundreds questioned. This situation has created a public climate of suspicion which has flavoured pre-existing psychopathogical states in local public service workers and administrators, as illustrated by five local managers who committed suicide after having being questioned.

Our patient, a 35-year-old health worker, employed in a major Milanese hospital, attempted suicide by jumping in front of a train. He was then admitted to hospital for minor bone injuries in an orthopaedic ward, where a psychiatric consultation was requested. At interview, he appeared over-sensitive and suspicious, and described meticulously his predicament, later coloured by delusional ideas with persecutory features and auditory hallucinations which led to a DSM-III-R Axis I diagnosis of delusional disorder (297.10), persecutory type.

The delusional ideas had appeared about two months earlier with associated anxiety, depression, insomnia and feelings of guilt about imagined shortcomings in his performance at work. Self-harm took place after reading a report of the arrest by Di Pietro of managers of the local health care system, which 